\title{
Striving for wellbeing: The different roles of hedonia and eudaimonia in goal pursuit and goal achievement
}

\author{
Kjærsti Thorsteinsen · Joar Vittersø
}

\begin{abstract}
Goals are central to theories of happiness and previous research has shown that successful goal pursuit typically leads to a boost in wellbeing. Taking these ideas further, the current study adopts the distinction between hedonic wellbeing (HWB) and eudaimonic wellbeing (EWB) and suggests that it is the former that increases when goals are achieved. By contrast, EWB is hypothesized to have a causal effect on the initiating and upholding of goal pursuits. In a short-term, longitudinal intervention study, 185 participants (78.8\% women): 69 students and 116 participants from a sample representative of the Norwegian population were asked to set a personal goal. Every night throughout the next week, participants received one out of three different mental exercises (i.e., mental contrasting, process simulation or positive fantasizing) to support active goal pursuit. A path model found that EWB, and not HWB, predicted subsequent goal effort directly $(\beta=.33, p<.001)$ and goal achievement indirectly (fully mediated by goal effort; $\beta=.14, p=.001)$. Further, the model showed that goal effort $(\beta=.17, p<$ $.001)$ and goal achievement $(\beta=.13, p=.001)$ caused an increase in post-intervention measures of HWB but not in EWB. A multilevel linear growth model revealed elevated levels of HWB for all intervention groups after the goal pursuit week $(\beta=.24, p<.001)$, while EWB in general did not change during the study period. However, EWB unexpectedly increased for those in the positive fantasizing condition. The present finding indicates that it is the eudaimonic part of wellbeing that ignites and sustains goal pursuit processes, at least when they take some effort. By contrast, HWB is less involved in goal pursuit initiatives and more related to the outcome phase. Results are discussed with reference to several wellbeing theories.
\end{abstract}

Keywords: subjective wellbeing, eudaimonic wellbeing, hedonic wellbeing, goal pursuit, goal achievement, effort

\section{Introduction}

Pursuing meaningful goals is a worthwhile activity. Indeed, Aristotle has convincingly argued that such a pursuit is the essence of a good life (e.g., Russell, 2013), and most modern conceptualizations of wellbeing are consistent with the idea that happiness increases when personally important goals either are about to be, or actually are being achieved (Brunstein, 1993; Cantor \& Sanderson, 1999; Carver \& Scheier, 1990; Diener, 1984; Diener, Suh, Lucas, \& Smith, 1999; Emmons, 1986; Klug \& Maier, 2015; Koestner, Lekes, Powers, \& Chicoine, 2002; Little, 1989; Smith, Tong, \& Ellsworth, 2014). Despite the consensus established for the view that successful goal pursuit leads to increased wellbeing, a related puzzle remains unsolved. It concerns the possibility that wellbeing might operate as both a cause and as an effect of goal pursuit, a situation often referred to as reciprocal causation. Hence, the purpose of the present paper is to investigate whether wellbeing, or certain dimensions of wellbeing, not only follows

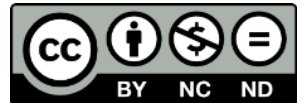


from goal achievement, but also ignites goal pursuing processes. In particular, we will analyze activities driven by goals that are somewhat difficult to reach.

The broaden-and-build theory of positive emotions (e.g., Fredrickson, 2001) is a renowned defender of a reciprocal wellbeing approach. Briefly, the idea is that positive emotions broaden one's momentary thought-action repertoires and consequently create an urge to explore novel thoughts and behaviors. Next, these thoughts and behaviors will build psychological, social and physiological resources. These resources lead in turn to higher wellbeing. Elevated wellbeing means more positive emotions, that again supply new thought-action repertoires, which then produce additional resources that cause better wellbeing, and so on in a neverending upward spiral.

But a growing literature contests the principal assumptions in the broaden-and-build theory. It seems that it is low arousal, and not positivity in itself, that constitutes the underlying mechanism of the broadening of attention and memory. This view is supported by observations showing how both negative and positive low-aroused affect broaden attention and memory, whereas high-aroused positive (and negative) affect actually narrow them down (Gable \& Harmon-Jones, 2008; Harmon-Jones, Gable, \& Price, 2013; Harmon-Jones, Price, Gable, \& Peterson, 2014). In addition, there are theoretical and empirical reasons to believe that an important function of low-arousal positive feelings - such as pleasure and satisfaction - is to give us more cognitive flexibility (Carver, 2003; Dreisbach \& Goschke, 2004). Consequently, pleasure and satisfaction prompt the shift from one goal pursuit to another, or to keep coasting on an activated but relatively effortless goal pursuit. Either way, pleasure does not typically motivate challenging activities and persistent goal pursuit (Luhmann \& Hennecke, 2017).

To find the kind of positive emotions that are capable of building psychological and physiological resources necessary in goal pursuit, one should probably look in the direction of high-aroused feelings such as interest, challenge and engagement (Kirby, Tugade, Morrow, Ahrens, \& Smith, 2014; Shiota, Thrash, Danvers, \& Dombrowski, 2014; Smith et al., 2014; Straume \& Vittersø, 2012; Vittersø, 2016). Hence, in order to understand the dialectics between goal pursuits, goal attainment and wellbeing, we suggest that the positive emotions that are included as elements of wellbeing are better differentiated into those that are hedonic (or benefit-related) and those that are eudaimonic (or opportunity-related). ${ }^{1}$ The present research aims at using this distinction in a longitudinal experimental design. We proceed toward this end by briefly reviewing the concept of wellbeing, and, in particular, the distinction between hedonic and eudaimonic wellbeing.

\section{Two forms of wellbeing: Hedonic and eudaimonic}

Most wellbeing researchers acknowledge that wellbeing is a multifaceted construct (Diener, Oishi, \& Tay, 2018; WHO, 2012) and a distinction is typically made between hedonic and eudaimonic forms (Gallagher, Lopez, \& Preacher, 2009; Henderson \& Knight, 2012; Tov, 2018). Hedonic wellbeing (HWB) concerns feelings and evaluations that are recognized as pleasant or unpleasant, what Kahneman refers to as the good-bad dimension of the human mind (Kahneman, 1999). It is further becoming conventional to regard the concept of subjective

\footnotetext{
${ }^{1}$ Several conceptualizations exist to account for the difference between what we refer to as hedonic and eudaimonic feelings, such as wanting versus liking (Berridge \& Kringelbach, 2013) and appetitive versus consummatory effects (Burgdorf \& Panksepp, 2006). Even the distinction between low aroused and high aroused positive feelings will often fit the characteristics of hedonic and eudaimonic feeling states, respectively. See Vittersø (2016) for a comprehensive review of this argument.
} 
wellbeing (SWB) as a kind of hedonic of wellbeing (e.g., Disabato, Goodman, Kashdan, Short, \& Jarden, 2016; Vittersø, 2016), although this conceptualization is debatable (Haybron, 2016).

Eudaimonic wellbeing (EWB) reflects a more complex concept than that of HWB, and no consensus about a taxonomy of EWB has yet been established (e.g., Vittersø, 2016). Historically, the term "eudaimonia" was merely the ancient Greek word for "a good life," thus both hedonic theories and different versions of Aristotelian theories of happiness were (competing) conceptualizations of eudaimonia (Keyes \& Annas, 2009; Nussbaum, 2001). More recently, however, the term "eudaimonia" - and particularly in the form of "eudaimonic wellbeing" - is taken to be a label placed on some variant of the Aristotelian accounts of how a good life ought to be lived (Haybron, 2016). As such, its philosophical heritage suggests that EWB must have something to do with optimal functioning in the sense of fulfilling one's human nature (Besser, 2016; Haybron, 2008). The essence of this notion has been summarized as "the state of being well and doing well in being well" (MacIntyre, 2007). Inspired by this philosophical literature, researchers have tried to translate the basic idea of eudaimonia into a scientific language, and we will discuss some of these attempts next.

In psychology, the most cited approaches to EWB have sprung out of the humanistic movement in the mid-20th century. For instance, the eudaimonic identity theory (Waterman, 1993; Waterman \& Schwartz, 2013), Ryff's version of psychological wellbeing (Ryff, 1989), and the self-determination theory (SDT; Ryan \& Deci, 2001; Ryan \& Martela, 2016) are all standing on humanistic shoulders in their respective focus on identity formation, positive mental health and organismic growth. The eudaimonic identity theory defines eudaimonia as the experience of personal expressiveness, which is the feeling that follows from having one's best potentials actualized. Eudaimonia is thus conceptualized as a particular kind of pleasure that also covers-but is not covered by-hedonia. Stated logically, eudaimonic feelings are a sufficient, but not a necessary condition for hedonic wellbeing. By contrast, Ryff's theory of eudaimonia contains no feeling element. Grounded in a synthesis of several humanistic theories, and strongly influenced by Jahoda's work on positive mental health (Jahoda, 1958), Ryff rather suggests that feelings are not relevant for the realization of personal potentialities, which she conceptualizes as the beautiful idea of purposeful life engagement (Ryff, 2016). Finally, the selfdetermination theory promotes a core eudaimonic idea in claiming that humans must live in accordance with their nature in order to live well. From the perspective taken by the SDT, living in accordance with one's nature means to satisfy the basic needs of autonomy, competence and relationships.

A fourth psychological conceptualization of EWB is offered by the functional wellbeing approach (FWA; Vittersø, 2013, 2016, 2018). Basically, it takes the Aristotelian point of view that in order to understand what wellness is, we must relate the concept to our nature. Further, the FWA suggests that at the most fundamental level, maintaining stability and fostering change are the two most essential features in the life of all biological organisms (e.g., Damasio, 2018; Pross, 2016). Consequently, a wellbeing theory should be able to account for how these fundamental processes of our nature are related to the central concepts of that theory. The explanation proposed by FWA is, in brief, that high levels of HWB are an indicator of wellfunctioning stability, whereas high levels of EWB are an indicator of well-functioning change processes. Finally, wellbeing is by the FWA considered to comprise both momentary feelings and a more stable orientation towards life. For HWB, the prototypical feeling is pleasure (operationalized as the frequency of felt pleasure, satisfaction and happiness) and for EWB the prototypical feeling is absorbed engagement (operationalized as the frequency of felt engagement, immersion and interest). The prototypical orientation to life in HWB is the 
tendency to evaluate oneself and one's environment as good rather than bad (operationalized as overall life satisfaction), and for EWB it is the inclination to develop one's potential as a human being (operationalized as personal growth).

The approaches presented above are just a few of the perspectives on EWB offered over the last two decades (e.g., Huta \& Waterman, 2014; Sheldon, 2018), suggesting that conceptual consensus remains to be established for this area of wellbeing research (e.g., Disabato et al., 2016 Kashdan, Biswas-Diener, \& King, 2008). However, a key difference between HWB and EWB can be identified across most of these approaches. It is that pleasure - as a feeling and/or as an attitude (i.e., life satisfaction) - constitutes the core element of HWB. The salient feature of EWB, on the other hand, is associated with the development of a person's potential as a human being. This distinction between two kinds of wellbeing-pleasure and satisfaction reflecting $\mathrm{HWB}$, and absorbed engagement and personal growth reflecting EWB - is the analytical foundation offered in the present study. An important implication of this conceptualization is that the FWA predicts that HWB is associated with successful goal achievement and low-effort activities, whereas EWB is associated with the initiation of difficult goal pursuits and with effortful activities.

\section{Goals and wellbeing}

The theories presented thus far also hold different views on the causal relationships between goals and wellbeing. For instance, the eudaimonic identity theory proposes that fulfilling certain identity goals will lead to increased EWB. By contrast, the SDT tells us that so-called intrinsic goals (i.e., those related to the fulfillment of psychological needs) do not cause eudaimonia, but rather constitute eudaimonia. When a person's EWB is sufficiently satisfied, the argument goes, then an increase in HWB will causally follow (Ryan \& Martela, 2016). As for the broaden-and-build theory, assumptions about the association between HWB and EWB are included in the model as a proposition about how high HWB causes an increase in EWB (Fredrickson, 2016). The psychological wellbeing approach has, to our knowledge, not articulated a causal model about the relationship between goals and wellbeing. Ryff and her colleagues have, however, documented a series of positive consequences of high EWB (e.g., Ryff, 2014, 2016; Ryff \& Singer, 2008). The functional wellbeing approach makes several predictions about goals and wellbeing. In particular, the FWA expects that EWB is associated with the initiation of so-called change goals, and that HWB is associated with stability goals (e.g., Luhmann \& Hennecke, 2017). The approach also predicts that HWB increases, at least temporarily, when a goal is achieved or a need is fulfilled.

Empirical evidence supports that goal achievement is associated with increases in HWB (Klug \& Maier, 2015; Koestner et al., 2002). Furthermore, a study by Sheldon and Lyubomirsky (2006) suggests that goal pursuit may have positive effects on EWB too, although only when the goal concerns activity change, rather than circumstantial change. Similarly, in a longitudinal study by Bauer and McAdams (2010) those adopting intellectual growth goals increased in EWB (ego development) over 3 years, while those who adopted socio-emotional goals increased in HWB (SWB). In line with the FWA, these studies indicate that change goals, i.e., intentional and effortful growth and activity goals, relate to EWB, while stability goals, i.e., goals concerned with ensuring secure circumstances and good social relationships, relate to HWB. McGregor and Little (1998) found that when we feel efficacy in our ability to reach a goal, we are rewarded with pleasurable feelings and positive evaluations of life (HWB); when a goal is integrated within core aspects of our sense of self, we experience a sense of meaning in life (EWB). Both efficacy and integrity are important aspects of how goals contribute to 
wellbeing; however, the science of wellbeing has tended to put more focus on efficacy and goal achievement.

\section{The concept of goals}

When it comes to wellbeing, there are differences between the process of pursuing one's goal (goal pursuit) and the result (goal achievement); between engaging in goal pursuit and attaining a desirable goal (e.g., Kaftan \& Freund, 2018). There is evidence that the level of goal progress, and the change in goal progress, can be more important than goal achievement for the relationship between goals and HWB (Hsee \& Abelson, 1991; Klug \& Maier, 2015; Steca et al., 2016). This gives backing to Carver and Scheier's (2001) principles of feedback control processes, where reducing the experienced discrepancy between the goal state and the state of reality at a fitting pace gives rise to positive affect (HWB). However, in a longitudinal study, Wiese and Freund (2005) found that it was the degree to which people were involved in pursuing their goals that was associated with an increase in HWB over the span of three years; reported progress had a weaker relationship to wellbeing. While feedback control processes have immediate effects on HWB, over time, continued engagement in significant goals (EWB) seems essential to a good life.

There is empirical support that wellbeing influences the goals we choose to engage in. For example, a study by Palys and Little (1983) found that people scoring higher on life satisfaction adopted goals with lower difficulty level and higher enjoyment than people scoring lower on life satisfaction. Similarly, Luhmann and Hennecke (2017) reported that across seven studies, high levels of life satisfaction were consistently associated with high levels of stability goals, and low levels of change goals. Considering that people do not put in more effort than they absolutely need to (Silvia, McCord, \& Gendolla, 2010), setting subordinate goals is not beneficial. While high HWB can be beneficial for stability (e.g., social relationships), for change (e.g., improving income, education, and political participation) a moderate level of HWB is better (Oishi, Diener, \& Lucas, 2007).

Related to this, research on self-regulation strategies shows that positive thoughts about goal achievement lower the chances of fulfilling a goal (Oettingen, Pak, \& Schnetter, 2001; Pham \& Taylor, 1999; Taylor, Pham, Rivkin, \& Armor, 1998). Further, in a series of experiments, Oettingen, Mayer, and Portnow (2016) found that those with positive fantasies invested lower effort in their goal pursuit, which predicted low success in attaining their goal, and consequently more depressive symptoms 1 to 7 months later. Although positive fantasies related to fewer depressive symptoms currently, over time-presumably by impeded goal pursuit-depressive symptoms increased. Thus, focusing on hedonic feelings and outcomes leaves us less motivated to improve current standings and thus worse off in the long run.

On the other hand, experiencing eudaimonic emotions such as curiosity, interest, awe and inspiration are central for helping us to keep working on something, even when it is difficult and not experienced as pleasant (e.g., Schwartz \& Wrzesniewski, 2016). These emotions motivate us to engage in novel things, solve puzzles and try at tasks for a longer period of time (Ainley, Hidi, \& Berndorff, 2002; Campos, Shiota, Keltner, Gonzaga, \& Goetz, 2013; Reeve, 1989; Straume \& Vittersø, 2012; Turner \& Silvia, 2006). Further, these feelings are connected to a disposition towards being growth-oriented and curious (Ainley et al., 2002; Kashdan \& Steger, 2007; Vittersø \& Søholt, 2011; Vittersø, Søholt, Hetland, Thoresen, \& Røysamb, 2010). Thus, in our longitudinal study, we expect EWB to operate as a predictor of effortful goal pursuit. 


\section{Improving goal pursuit}

Analogous to the research presented on hedonic feeling states, Oettingen and Reininger (2016) found that positive outcome thinking reduces goal pursuit effort and leads people to behave as though they already have attained their goal, thus sapping energy and reducing goal achievement. However, thinking about the future in a systematic manner, evoking emotional states and producing links to action, can be beneficial for self-regulating towards a goal (Baumeister, Vohs, \& Oettingen, 2016; Masicampo \& Baumeister, 2013; Taylor et al., 1998). Our focus is on two traditions of imagery techniques that both have proved effective in improving goal pursuit: mental contrasting (Johannessen, Oettingen, \& Mayer, 2012; Oettingen, Marquardt, \& Gollwitzer, 2012; Oettingen, Mayer, \& Thorpe, 2010; Oettingen et al., 2001; Oettingen, Stephens, Mayer, \& Brinkmann, 2010; Sheeran, Harris, Vaughan, Oettingen, \& Gollwitzer, 2013) and process simulation (Pham \& Taylor, 1999; Taylor et al., 1998).

Both mental contrasting and process simulation tone down the positive outcome focus, and, in its place, introduce aspects of reality and energize towards action. However, there are essential differences between the two: in mental contrasting, the focus is on identifying what it is in you that could hinder goal pursuit; in process simulation, the focus is on the activities and steps that you need to go through in order to meet your goals. Also, importantly, in mental contrasting, you first activate the positive fantasy outcome and then focus on the obstacles and the behavior that will help overcome those obstacles, which is thought to induce a necessity to act by changing the interpretation of reality as an obstacle to wish fulfillment (Oettingen et al., 2001). In process simulation, the weight is put on mentally visualizing actually going through the motions involved in goal pursuit by visualizing taking the right steps and putting in the effort (Pham \& Taylor, 1999; Taylor et al., 1998). Both mental contrasting and process simulation have previously proved effective compared to positive fantasizing and outcome thinking. In this study, in order to further the goal pursuit process, our participants practiced either mental contrasting, process simulation or positive fantasizing every night for a week. By investigating all three mental exercises simultaneously, we wanted to explore if the differences presented above would give rise to detectable differences in wellbeing.

\section{The present study}

The overarching purpose of the present study is to use both HWB and EWB in exploring how wellbeing and goal pursuit relate to each other. We designed a longitudinal intervention experiment, with electronic deliverance of interventions to aid in goal pursuit, so that we were able to examine wellbeing as both predictor and outcome variables in the same study. We expect to find that the role of HWB and EWB in goal pursuit conforms to the prediction deduced by the functional wellbeing approach as follows.

1) EWB is a stronger predictor of effortful goal pursuit than HWB.

2) The effect of successful goal achievement is stronger on HWB than on EWB.

3) Goal effort will facilitate goal achievement.

A second aim of the study is to explore how different strategies of goal pursuit may relate to wellbeing. More concretely, we expect mental contrasting and process simulation to show greater increase in HWB than positive fantasizing, due to their influence on goal achievement reported in earlier studies. Following common practice in wellbeing research, we will also check whether gender and social status (being a student versus a member of the general population) have an impact on the dependent variables. 


\section{Method}

\subsection{Participants and procedure}

We recruited participants to the "Happiness as a goal" study through two routes: 1) by advertising it in class and sending an invitation email to a convenience sample of psychology students at a Norwegian university, and 2) by sending an invitation letter to a representative Norwegian sample of 2,000 addresses. In order to be eligible to participate, one needed to own and know how to use a smart phone with Internet access. One hundred and eighty-five participants (34 men and 127 women) volunteered for the study: 69 from the student population and 116 from the general population. They ranged in age from 21 years to 77 years, with a mean age of $36.08(S D=13.44)$. Twenty-four participants did not report their age and gender. The study was administered exclusively online, using Qualtrics, an online survey platform (https://www.qualtrics.com), in combination with SurveySignal (http://www.surveysignal.com) for sending text messages to mobile phones. Volunteers found their way to our information site by going to the link in our invitation e-mail/letter: by ticking "yes" to the informed consent question, they were randomized into one of three groups and sent to the registration site in SurveySignal.

After registering, participants in all three groups completed an identical questionnaire (T1) and were asked to set a goal that was "a little challenging, but achievable." The goals adopted were variable in terms of content, for example, personal goals reported by the participants included "quit smoking," "exercise more," "get a good grade in my exam" and "save money." After writing down their personal goal, all three groups were also asked to perform a mental exercise; however, the instructions for the mental exercises differed by group. The mental exercises are described in more detail in the next section, briefly: Group 1 received instructions for mental contrasting (MC, $n=52$, Oettingen et al., 2001), Group 2 received instructions for positive fantasizing (PF, $n=61$, Oettingen et al., 2001), and Group 3 received instructions for process simulation (PS, $n=72$, Pham \& Taylor, 1999). Participants were then informed that they would be asked to complete the same mental exercise every night for the following 7 days. At 9 pm, a text message that included a link to a daily report form was sent out to participants' mobile phones. The daily report forms consisted of instructions for their assigned mental exercise and a short questionnaire. After one week of working with their goal and completing daily reports, participants filled out the second questionnaire (T2), and one week after that (15 days after the initial questionnaire) they completed a follow-up questionnaire (T3) with the same measures as at $\mathrm{T} 2$.

Participants received a gift certificate of 200 Norwegian kroner (NOK; approximately equivalent to 20 Euro or 24 USD) for completing T1, the daily report forms and T2-and an additional gift certificate of 100 NOK for completing the follow-up at T3. In the student sample, we had a raffle for a bonus gift certificate of 5000 NOK amongst the students who completed all measures. The study was approved by the Norwegian Centre for Research Data.

\subsection{Measures}

We measured hedonic and eudaimonic dimensions of wellbeing as follows.

Life satisfaction. A short three-item version of the Satisfaction With Life Scale (SWLS; Diener, Emmons, Larsen, \& Griffin, 1985) was used to capture life satisfaction. Participants were asked to evaluate to what extent the following items were true for them on a scale from 1 (not true) to 7 (completely true). The items included were: "In most ways my life is close to my ideal," "The conditions of my life are excellent" and "I am satisfied with my life." Cronbach's 
alphas were .87 at T1, .86 at T2 and .88 at T3. Summary statistics across groups and time were $M=4.93, S D=1.15$.

Trait emotions. Pleasure, interest and negative emotions were measured by the Basic Emotion Trait Test (BETT; Vittersø, Oelmann, \& Wang, 2009). All variables were measured by three items each: pleasure was measured by pleasure, satisfaction and happiness; interest by interest, immersion and engagement; and negative emotions by anger, sadness and fear. Instructions asked participants how often they felt each of the emotions in their everyday life, with response options running from 1 (never) to 7 (all the time). Cronbach's alphas at T1, T2 and T3 were $.88, .88$ and .91 for the pleasure subscale; $.86, .83$ and .89 for the interest subscale; and $.65, .73$ and .75 for the negative emotions subscale. Summary statistics across groups and time were $M=4.67, S D=1.00$ for pleasure, $M=4.87, S D=1.05$ for interest, and $M=2.58, S D=$ 0.90 for negative emotions.

Personal growth composite. The instrument comprises four subscales: curiosity (Amabile, Hill, Hennessey, \& Tighe, 1994) with three items, absorption (Kashdan, Rose, \& Fincham, 2004) with three items, complexity (from Cattell's 16PF, see IPIP, 2002) with three items, and competence (from Cloninger's TCI, see IPIP, 2002) with three items. The participants responded on a 5-point response format from 1 (strongly disagree) to 5 (strongly agree). Example items are: "I enjoy trying to solve complex problems" (curiosity), "When I am participating in an activity, I tend to get so involved that I lose track of time" (absorption), "I love to think up new ways of doing things" (complexity), and "I can perform a wide variety of tasks" (competence). Cronbach's alphas were .80 at T1, .81 at T2 and .75 at T3. Summary statistics across groups and time were $M=3.61, S D=0.56$.

Goal effort and achievement. We measured goal effort and goal achievement at both T2 and T3 with one item each. Goal effort was measured with the question: "How much effort have you put in to reach your goal?" with answer alternatives ranging from 1 (very little) to 5 (a lot). Summary statistics for goal effort across groups and T2 and T3 measures were $M=3.14, S D=$ 0.94. Goal achievement was measured by the item: "Do you feel that you have reached your goal during this week?" The response options were $1=$ yes $(n=45)$ and $0=$ no $(n=83)$.

Time. Our wellbeing variables were measured three times over a two-week period: before the intervention (T1), directly after the intervention week (T2) and one week after the intervention ended (T3). The time-variable was scaled such that the intercept represents the model-implied mean at the first time-point and the coefficient is the increase from the beginning to the end, i.e., $\mathrm{T} 1=0, \mathrm{~T} 2=0.5$ and $\mathrm{T} 3=1$.

Intervention groups. We effect coded the groups such that the intercept represents the grand mean of the dependent variable for all three groups (Alkharusi, 2012).

\subsection{Interventions}

In the daily report forms, we first asked participants in all three intervention groups to think of their goal (participants' individual goals were integrated into the instructions) and follow the instructions for the exercises. The exercises took approximately the same amount of time to complete. They differed only with regard to the instructions.

The Mental Contrasting intervention was adapted from Oettingen et al. (2001). Participants receiving this intervention were asked to first identify one positive aspect about achieving the goal, to picture events and experiences connected to the positive outcome, and to write down a few words describing what they thought about it. They were then asked to identify one negative aspect of the current situation that stands in the way of achieving their goal, and in the same manner, picture events and experiences connected to this obstacle and write down a few 
words describing what they thought about it. The exercise is designed to create a mental contrast between the positive fantasy of the goal and the negative aspects of the present that may hinder goal achievement, and ultimately, induce a feeling in the participants of the necessity to act.

In the Positive Fantasizing condition, participants were given the same instructions as for the Mental Contrasting, except that they were not asked to think about a negative aspect (Oettingen et al., 2001). Instead, they were asked to think about another positive aspect. That is, instead of creating a contrast to the positive aspect, people were only allowed to fantasize about the positive outcomes of realizing one's goals.

The Process Simulation intervention was adapted from Taylor and colleagues (Pham \& Taylor, 1999; Taylor et al., 1998). Here participants were asked to think about the processes they needed to go through, picture themselves collecting materials or resources, and, in as detailed and realistic a way as possible, see themselves completing the tasks that would lead to goal achievement. This mental exercise is designed to help participants identify activities and steps involved in goal achievement, which prompts them to form a plan for how they are going to achieve their goal. Also, the mental exercise may help anticipate and regulate emotions that occur while working towards the goal.

\subsection{Data reduction and preliminary analysis}

We used IBM SPSS version 24 and Mplus version 8 for our analysis. A principal component analysis (PCA) of our wellbeing variables at T1, T2, and T3 showed that variables consistently loaded on two factors (with Eigenvalues $>1$ ). SWLS, pleasure and negative emotions loaded on one factor; personal growth and interest loaded on the other factor. There were no crossloadings $>.5$. We composed hedonic wellbeing (HWB) as SWLS + pleasure - negative emotions (negative loading) and eudaimonic wellbeing (EWB) as personal growth + interest. HWB and EWB were standardized for the analyses.

The analysis dataset consisted of 167 responses at T1, 128 responses at T2 and 107 responses at T3 $=402$ observations (out of $185 \times 3=555$ possible, $72,43 \%$ ). Data missing for the wellbeing variables were imputed using multiple imputations as follows. When still organized as a wide file (i.e., one record/row of data per participant), all variables belonging to the HWB construct were used as input for the EM imputation algorithm as provided by IBM SPSS. A similar procedure was used for the variables belonging to the EWB construct. Thus, the imputation was completed in two steps, first by including the HWB variables from all three waves, and then a new estimation using the EWB variables from the three waves.

We combined the T2 and T3 measures of goal effort and goal achievement and used an average of T2 and T3 for EWB2 and HWB2 in the path model presented in Figure 1 below, for the purpose of keeping the maximum number of participants in our analysis and for parsimony. The intraclass correlation coefficient (ICC) was .84 for HWB and .78 for EWB, thus the multilevel analyses reported in Tables 1 and 2 below were appropriate.

\section{Results}

\subsection{Wellbeing, goal effort and goal achievement}

We hypothesized EWB to be a stronger predictor of effortful goal pursuit than HWB, because EWB affects goal effort, which in turn predicts goal achievement. We tested this hypothesis by fitting the path model depicted in Figure 1 to our data. We did not include the intervention groups in this model because a preliminary analysis showed that the three groups differed 
neither on goal effort, $F(2,127)=0.06, p=.946$, nor on goal achievement, $F(2,127)=1.33, p=$ .269. The model was estimated with Robust Maximum Likelihood (MLR) and had excellent goodness-of-fit, $\chi^{2}(2, N=185)=3.80, p=.149, C F I=1.00, R M S E A=.07,90 \%$ CI $[.00, .18]$. In line with the first part of our hypothesis, EWB at T1 significantly predicted goal effort directly and goal achievement indirectly, whereas neither of these paths were significant for HWB at T1. The total standardized effect from EWB at T1 to goal achievement was $\beta=.23, p=.017$, with the direct effect equal to $\beta=.10(p=.306)$ and the indirect effect equal to $\beta=.14(p=.001)$. The indirect effect is simply the path from EWB to goal effort times the path from goal effort to goal achievement. The total effect from HWB at T1 to goal achievement was $\beta=.15, p=.128$; the direct effect $\beta=.09, p=.285$; and the indirect effect $\beta=.05, p=.258$. We also tested the difference between the model depicted in Figure 1 and a nested model in which the paths from EWB at T1 to goal effort and the path from HWB at T1 to goal effort were constrained to be equal. A Satorra-Bentler chi-square difference test for robust ML estimation showed a significant difference in goodness-of-fit between the two models, $\Delta \chi^{2}(1)=3.96, p=.047$. This result indicates that the impact from EWB on goal effort is significantly stronger than the impact from HWB on goal effort. Using the same modelling strategy, no difference in the strengths of the paths from EWB at T1 and HWB at T1 on goal achievement was observed, $\Delta \chi^{2}(1)=0.10, p=$ .746 .

Figure 1. Standardized regression weights for a path model of goal effort as a mediator between wellbeing and goal achievement. Estimates from a model without the goal effort variable in parenthesis.

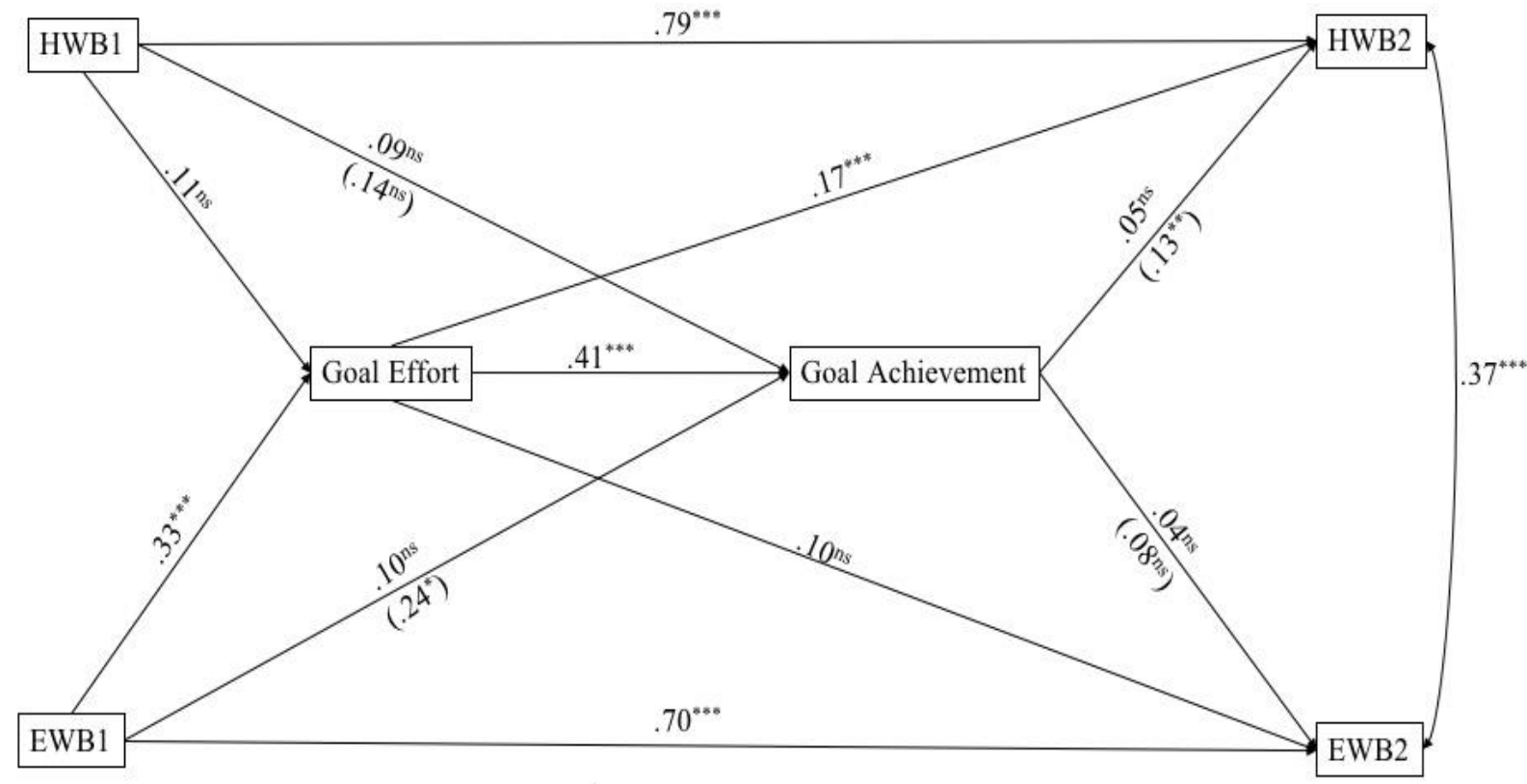

ns $=$ not significant. ${ }^{*} \mathrm{p}<.05 .{ }^{* *} \mathrm{p}<.01 .{ }^{* * *} \mathrm{p}<.001$.

In a model estimated without the goal effort variable, a significant path was found from goal achievement to HWB at T2, $\beta=.13, p=.001$, whereas the path from goal achievement to EWB at T2 was not significant, $\beta=.08, p=.144$. Constraining the two paths to be equal gave a significantly worse goodness-of-fit in the nested model, $\Delta \chi^{2}(1)=4.27, p=.039$. Again, this means that the association from goal achievement to HWB is significantly stronger than the association from goal achievement to EWB. 
When goal effort was included as a mediator in the model, the path from goal achievement to HWB at T2 was no longer significant and the chi-square of a nested model constraining the two paths to be equal was not different from the chi-square of a model in which the two paths were not constrained to be equal, $\Delta \chi^{2}(1)=0.52, p=.470$. This suggests that even if goal achievement in itself is an important predictor of HWB, our data indicate that it is the effort invested in reaching a goal that really drives the association between goal achievement and HWB.

Finally, the path from goal effort to HWB at T2 was significant, $\beta=.17, p<.001$, while the path to EWB at T2 was not, $\beta=.10, p=.109$. Constraining the two paths to be equal gave a significantly worse goodness-of-fit in the nested model, $\Delta \chi^{2}(1)=6.43, p=.011$, illustrating the importance of goal effort on goal achievement, and further supporting the part of our hypothesis that expected the effect from goal effort on HWB to be stronger than its effect on EWB.

\subsection{Multilevel model of change in wellbeing}

We further investigated how the one week of active goal pursuit contributed to changes in EWB and HWB during the study period. For that purpose, we specified and estimated two multilevel linear growth models: one for HWB and one for EWB. Both models included a random intercept in order to take each participant baseline score into account; and both models included the same level-2 covariates: gender, age and student vs. general population survey sample. Although the intervention groups did not differ in terms of goal achievement, we still wanted to investigate if the different interventions influenced the wellbeing measures. We expected no intervention group differences in initial levels of wellbeing, as our participants were randomized to the groups. Our focal explanatory variable at level- 1 was time and our research question was if the intervention period of working towards a personal goal influenced either EWB and HWB, or both.

\subsubsection{Hedonic wellbeing}

The results for HWB are reported in Table 1 below. The significant time-variable indicates that HWB increased for all three intervention groups, $\beta=.24, p<.001$, after the goal pursuit period. Our hypothesis that participants practicing MC or PS would increase more in HWB, while participants in the PF-group would not, was not supported. That is, neither MC nor PS had a significant interaction effect with time. There were also no differences between students/general population, male/female and age.

\subsubsection{Eudaimonic wellbeing}

The results for EWB are reported in Table 2 below. In contrast to HWB, there was no general time-trend for EWB. However, unexpectedly, the positive fantasy group increased significantly more than all groups combined on EWB, $\beta=.29, p<.001$ ). Age was also significant in our model. This finding means that reported EWB increased with .02 scale point per year.

For both $\mathrm{HWB}$ and $\mathrm{EWB}$, the variances for the intercepts are relatively large compared to their standard errors $(Z=2.23, p=.026$ and $Z=2.66 p=.008$ respectively), indicating that there is substantial between-person heterogeneity within the intervention groups. The within-person random effects are also large and there is evidence of auto-correlation in the within-person residuals, thus there is uncertainty in the estimates of typical patterns. 
Table 1. Results from the multilevel growth model for hedonic wellbeing $(\mathrm{N}=161)$

\begin{tabular}{|c|c|c|c|c|c|c|}
\hline \multirow[b]{2}{*}{ Fixed effects (intercept, slopes) } & \multirow[b]{2}{*}{ Estimate } & \multirow[b]{2}{*}{$(\mathrm{SE})$} & \multirow[b]{2}{*}{$\mathrm{t}$} & \multirow[b]{2}{*}{$p$} & \multicolumn{2}{|c|}{ CI95 } \\
\hline & & & & & Lower & Upper \\
\hline Intercept (level at week 1) & -.47 & 0.31 & -1.50 & .135 & -1.09 & 0.15 \\
\hline Time & .24 & 0.05 & 4.66 & $<.001$ & 0,14 & 0.34 \\
\hline $\mathrm{MC}$ & .17 & 0.12 & 1.472 & .143 & $-0,06$ & 0.40 \\
\hline PF & -.01 & 0.11 & -0.90 & .372 & -0.32 & 0.12 \\
\hline PS & -.07 & 0.11 & -0.69 & .493 & -0.28 & 0.14 \\
\hline Time $^{*} \mathrm{MC}$ & -.03 & 0.08 & -0.34 & .735 & -0.18 & 0.12 \\
\hline Time $^{*} \mathrm{PF}$ & -.02 & 0.07 & -0.27 & .784 & -0.16 & 0.12 \\
\hline Time*PS & .05 & 0.07 & 0.66 & .508 & -0.09 & 0.18 \\
\hline Students & .37 & 0.20 & 1.88 & .062 & -0.02 & 0.76 \\
\hline Gender & -.23 & 0.18 & -1.28 & .202 & -0.60 & 0.13 \\
\hline \multirow[t]{2}{*}{ Age } & .01 & 0.01 & 1.15 & .254 & -0.01 & 0.02 \\
\hline & & & & & \multicolumn{2}{|c|}{ CI95 } \\
\hline Random effects ((co-)variances) & Estimate & $(\mathrm{SE})$ & $z$ & $p$ & Lower & Upper \\
\hline \multicolumn{7}{|l|}{ Level 2 (between-person) } \\
\hline Intercept & .37 & 0.17 & 2.23 & .026 & 0.15 & 0.90 \\
\hline \multicolumn{7}{|l|}{ Level 1 (within-person) } \\
\hline Residual & .67 & 0.15 & 4.48 & $<.001$ & 0.27 & 0.87 \\
\hline Autocorrelation & .58 & 0.19 & 3.09 & .002 & 0.31 & 1.10 \\
\hline
\end{tabular}

Note: Time was coded $0=\mathrm{T} 1, .5=\mathrm{T} 2$ and $1=\mathrm{T} 3$, groups were effect coded; students were coded $1=$ student, $0=$ general population; gender was coded $1=$ female, $0=$ male; age was grand-mean centered; $\mathrm{MC}=$ mental contrasting; $\mathrm{PF}=$ positive fantasizing; $\mathrm{PS}=$ process simulation .

Table 2. Results from the multilevel growth model for eudaimonic wellbeing $(N=161)$

\begin{tabular}{|c|c|c|c|c|c|c|}
\hline \multirow[b]{2}{*}{ Fixed effects (intercept, slopes) } & \multirow[b]{2}{*}{ Estimate } & \multirow[b]{2}{*}{$(\mathrm{SE})$} & \multirow[b]{2}{*}{$\mathrm{t}$} & \multirow[b]{2}{*}{$p$} & \multicolumn{2}{|c|}{ CI95 } \\
\hline & & & & & Lower & Upper \\
\hline Intercept (level at week 1) & -.78 & 0.30 & -2.60 & .010 & -1.38 & -0.19 \\
\hline Time & .11 & 0.06 & 1.72 & .087 & -0.02 & 0.23 \\
\hline MC & .19 & 0.12 & 1.61 & .109 & -0.04 & 0.41 \\
\hline $\mathrm{PF}$ & -.19 & 0.11 & -1.75 & .081 & -0.41 & 0.02 \\
\hline PS & .01 & 0.10 & .06 & .954 & -0.20 & 0.21 \\
\hline Time $^{*} \mathrm{MC}$ & -.13 & 0.09 & -1.40 & .165 & -0.31 & 0.05 \\
\hline Time*PF & .29 & 0.09 & 3.31 & .001 & 0.12 & 0.46 \\
\hline Time*PS & -.16 & 0.08 & -1.92 & .056 & -0.32 & 0.00 \\
\hline Students & .25 & 0.19 & 1.33 & .186 & -0.12 & 0.62 \\
\hline Gender & .07 & 0.18 & 0.38 & .708 & -0.28 & 0.41 \\
\hline \multirow[t]{2}{*}{ Age } & .02 & 0.01 & 2.52 & .013 & 0.00 & 0.03 \\
\hline & & & & & \multicolumn{2}{|c|}{ CI95 } \\
\hline Random effects ((co-)variances) & Estimate & $(\mathrm{SE})$ & $z$ & $p$ & Lower & Upper \\
\hline \multicolumn{7}{|l|}{ Level 2 (between-person) } \\
\hline Intercept & .48 & 0.18 & 2.66 & .008 & 0.23 & 0.99 \\
\hline \multicolumn{7}{|l|}{ Level 1 (within-person) } \\
\hline Residual & .62 & 0.15 & 4.22 & $<.001$ & 0.25 & 0.83 \\
\hline Autocorrelation & .46 & 0.19 & 2.40 & .016 & 0.20 & 1.05 \\
\hline
\end{tabular}

Note: Time was coded $0=\mathrm{T} 1, .5=\mathrm{T} 2$ and $1=\mathrm{T} 3$, groups were effect coded; students were coded $1=$ student, $0=$ general population; gender was coded $1=$ female, 0 = male; age was grand-mean centered; $\mathrm{MC}=$ mental contrasting; $\mathrm{PF}=$ positive fantasizing; $\mathrm{PS}=$ process simulation. 


\section{Discussion}

Our results suggest that hedonia and eudaimonia play different roles in the reciprocal relationship between wellbeing and goal pursuit. Using a longitudinal design, we learned that eudaimonic wellbeing helped activate and advance effortful goal pursuit, whereas an intensive week of goal pursuit was rewarded by increased hedonic wellbeing. We found that people higher in eudaimonic wellbeing put more effort towards their goal and were consequently more likely to achieve it. Hedonic wellbeing did not play a significant role in this part of the process, although the consequences of goal effort and goal achievement were increased hedonic wellbeing. We did not find the expected differences between the intervention groups.

The results are in line with the predictions derived from the FWA (Vittersø, 2013, 2016). The FWA claims that processes involved in effortful growth processes, such as embarking on a difficult goal pursuit, are related to EWB rather than HWB. The latter operates as a reward for goal achievement, but not as a motivator for the goal striving. The results are also compatible with the SDT (Ryan \& Deci, 2017), which argues that HWB is the outcome variable and EWB is the causal variable of a goal process. However, the results partly contradict the predictions made by the broaden-and-build theory, because Fredrickson argues that both eudaimonic and hedonic emotions contribute to increased goal effort (e.g., Fredrickson, 2001, p. 219). In our data, only the eudaimonic part of wellbeing did that.

A salient distinction between the FWA and the SDT concerns the conceptualization of wellbeing. For example, according to the FWA, the concept of wellbeing is not considered to be a state, but a process that includes those elements of human development that typically are referred to as optimal functioning-i.e., the process of development in and by itself. Hence, when people feel engaged as they execute a challenging task, this feeling is in itself a positive experience. As such, it is a part of that person's wellbeing, even if it is not labelled as pleasure or satisfaction. By contrast, the SDT considers the engaged experience that often occurs during the early phases of a goal pursuit as a cause of wellbeing, and not as wellbeing in itself. In other words, the SDT makes a sharp distinction between the feelings we have as we execute a plan that leads to a goal, and the feelings we have when the goal is reached. The former feeling state is not part of their wellbeing concept, whereas the latter is. The authors are, however, strongly aware of the fact that the results presented here are incapable of solving this important conceptual disagreement.

\subsection{Eudaimonic wellbeing, goal effort and goal pursuit}

The present findings indicate that it is the eudaimonic part of wellbeing that ignites and sustains goal pursuit processes, at least when they take some effort. By contrast, the hedonic dimension of wellbeing is less involved in goal pursuit initiatives and more related to the outcome phase. This finding is supported by existing theory and research outlining how EWB and interest encourage processes typical for focused goal pursuit (Campos et al., 2013; Schwartz \& Wrzesniewski, 2016; Straume \& Vittersø, 2012). Although we did not observe an effect from HWB on goal effort, our results do not corroborate the literature reporting that HWB and pleasure actually obstruct focused goal pursuit processes (Carver, 2003; Dreisbach \& Goschke, 2004; Oettingen et al., 2016). Nevertheless, our results show that EWB was positively correlated with subsequent goal effort and goal achievement, whereas HWB kicked in at a later stage of the timeline. In sum, it appears that when the influence of eudaimonic and hedonic wellbeing is simultaneously compared, the existing influence of wellbeing on goal pursuit essentially takes place through EWB. That is, when controlling for HWB, eudaimonia was found to make an independent contribution to both goal effort and goal achievement. By 
contrast, when controlling for EWB, hedonia did not make a similar independent contribution to either goal effort or goal achievement. It would thus appear that when it comes to the two main concepts of wellbeing, EWB is important for getting challenging projects started and HWB is important in rewarding successful task completion.

The present study also shows that goal effort can help explain why the two forms of wellbeing have a differentiated impact on goal achievement. Indeed, our results show that eudaimonic wellbeing constitutes a more important inner psychological resource for improving goal pursuit because it promotes adaptive forms of coping under challenge, by increasing effort towards the goal.

One result that puzzled us was that the positive thinking intervention group actually increased in eudaimonic wellbeing during the study, compared to the other two groups. This finding was surprising, and we cannot rule out the possibility that it actually was an artefact of the uncertainty connected to the high heterogeneity in our sample. Another possibility is that the period of only thinking positively about goal outcomes left participants wanting to do something. For example, Taylor et al. (1998) found that although the outcome simulation group failed to take action to achieve their goals during the study period, they were left highly motivated.

\subsection{Goal pursuit, goal achievement and hedonic wellbeing}

Our findings revealed that goal pursuit and goal achievement produce increases in hedonic wellbeing. The positive correlation between goal pursuit and HWB is well-established (Klug \& Maier, 2015; Koestner et al., 2002), but the current findings add to previous studies that have shown a causal relationship by using a longitudinal, experimental design (MacLeod, Coates, \& Hetherton, 2008; Steca et al., 2016). In our study, HWB increased after the intervention period where participants engaged in goal pursuit. Also, the path model showed that the output of goal pursuits increased subsequent $\mathrm{HWB}$, adding to the evidence that a major function of HWB is to reward goal fulfillment.

Our analyses did not detect any differences between the three interventions in goal outcomes and HWB. Previous investigations by Oettingen and colleagues (Johannessen et al., 2012; Kappes, Singmann, \& Oettingen, 2012; Oettingen, Mayer, et al., 2010; Oettingen et al., 2001), comparing mental contrasting and positive fantasizing, have found mental contrasting to be more effective than positive fantasizing alone in improving goal pursuit. Process simulation has also led to more successful goal outcomes in the past (Pham \& Taylor, 1999; Taylor et al., 1998). In our study, the lack of differences between intervention groups may be explained by the heterogeneity in the goals our participants set and/or the short time-perspective of the study. Also, for mental contrasting to be successful, participants need to have a high expectation of success, and we did not incorporate this into our analyses.

\section{Limitations and conclusion}

When comparing the changes in wellbeing, we did not have a control group (i.e., a group that did not engage in goal pursuit), thus we cannot be sure that it was the goal pursuit per se that actually increased HWB. However, subjective wellbeing, which we used to measure HWB, is thought to reflect the actual conditions in a person's life and has been shown to be relatively stable over time (Costa, McCrae, \& Zonderman, 1987; Schimmack, Schupp, \& Wagner, 2008), but still sensitive to short-term goal pursuits (Steca et al., 2016). Thus, it is reasonable to assume that the observed increase in HWB during our study stems from goal pursuit and goal achievement. 
Although we took means to recruit a representative national sample, the participants did actively self-recruit. Thus, there might be some characteristics of our participants (high motivation) that may limit the generalizability of our results to the general population. Moreover, the response rate for the population study was very low, which makes it difficult to generalize the present findings to the population in general. However, the fact that a sample originating from a population representative of Norwegians was included in the study must be considered a strength in itself, given the extreme bias in the number of student samples utilized in psychological research. Moreover, recent studies suggest that even samples with very low response rates appear to do a good job in making predictions about the population from which they are drawn (Hellevik, 2016).

Previous studies have shown that wellbeing outcomes can be differentiated based on goal types, but because participants were free to pursue any goal of their interest, and were asked to set a personally meaningful goal, we did not take measures to differentiate between different types of goals in our analyses (e.g., zero-sum vs. non-zero-sum goals, intrinsic vs. extrinsic goals, self-concordant vs. controlled goals; Headey, 2008; Kasser \& Ryan, 2001; Sheldon \& Houser-Marko, 2001). Our results accordingly reflect that people were instructed to set personally meaningful and slightly difficult goals.

The hypotheses offered in the study were basically supported by significant results. However, the effect sizes were not very large. An explanation might be that the study was conducted in a natural setting, which increases the number of potential influences dramatically compared to a controlled laboratory setting. However, in a natural setting, even small effect sizes can have important implications for theory and practice (Abelson, 1985). Although the findings contribute to a more differentiated understanding of the dynamic interaction between wellbeing and goal processes, there are obviously other mechanisms involved in the regulation of goal-oriented activities. For example, in a natural setting, people pursue multiple goals in tandem, and active goals pull resources away from each other (Kruglanski et al., 2002). Participants in this study were asked to set and report on only one specific goal, thus, we do not know the influence of competing goals. This might be an interesting path that future studies could explore.

In sum, and despite these limitations, the present paper adds to the previous research on wellbeing and goals by identifying the unique functioning of EWB and HWB in processes involving goal pursuit and goal achievement. This speaks to the importance of distinguishing between eudaimonic and hedonic dimensions of wellbeing. If wellbeing truly is a process and not a place-as Diener and Biswas-Diener (2008) have suggested-it is important to fully realize the phenomenological richness and diverse valuations involved in a life well lived. A science of wellbeing should aspire to comprehend the complexity of subjective experiences and not narrow its scope to the study of pleasure and satisfaction alone. The experience of stepping out of one's comfort zone is different from that of returning to a safe haven. The first can be exciting and even frightening; the second is typically felt as pleasant and rewarding. But both contribute to a good life-and together with other positive affects and judgments, they should be included in a scientist's understanding of what "being well and doing well in being well" means.

\section{Authors}

Kjærsti Thorsteinsen

UiT The Arctic University of Norway

kjarsti.thorsteinsen@uit.no 
Joar Vittersø

UiT The Arctic University of Norway

Publishing Timeline

Received 8 May 2018

Accepted 19 August 2018

Published 9 December 2018

\section{References}

Abelson, R. P. (1985). A variance explanation paradox: When a little is a lot. Psychological Bulletin, 97(1), 129-133. https://doi.org/10.1037/0033-2909.97.1.129

Ainley, M., Hidi, S., \& Berndorff, D. (2002). Interest, learning, and the psychological processes that mediate their relationship. Journal of Educational Psychology, 94(3), 545-561. https://doi.org/10.1037/0022-0663.94.3.545

Alkharusi, H. (2012). Categorical variables in regression analysis: A comparison of dummy and effect coding. International Journal of Education, 4(2), 202-210. https://doi.org/10.5296/ije.v4i2.1962

Amabile, T. M., Hill, K. G., Hennessey, B. A., \& Tighe, E. M. (1994). The Work Preference Inventory: Assessing intrinsic and extrinsic motivational orientations. Journal of Personality and Social Psychology, 66(5), 950-967. https://doi.org/10.1037/0022-3514.66.5.950

Bauer, J. J., \& McAdams, D. P. (2010). Eudaimonic growth: Narrative growth goals predict increases in ego development and subjective well-being 3 years later. Developmental Psychology, 46(4), 761-772. https://doi.org/10.1037/a0019654

Baumeister, R. F., Vohs, K. D., \& Oettingen, G. (2016). Pragmatic prospection: How and why people think about the future. Review of General Psychology, 20(1), 3-16. https://doi.org/10.1037/gpr0000060

Berridge, K. C., \& Kringlebach, M. L. (2013) Neuroscience of affect: Brain mechanisms of pleasure and displeasure. Current Opinion in Neurobiology, 23(3), 294-303. https://doi.org/10.1016/j.conb.2013.01.017

Besser, L. L. (2016). Conceptual challenges for a science of eudaimonic well-being. In J. Vittersø (Ed.), Handbook of eudaimonic well-being (pp. 85-91). Cham, Switzerland: Springer International. https://doi.org/10.1007/978-3-319-42445-3 5

Brunstein, J. C. (1993). Personal goals and subjective well-being: A longitudinal study. Journal of Personality and Social Psychology, 65(5), 1061-1070. https://doi.org/10.1037/0022-3514.65.5.1061

Burgdorf, J., \& Panksepp, J. (2006). The neurobiology of positive emotions. Neuroscience \& Biobehavioral Reviews, 30(2), 173-187. https://doi.org/10.1016/j.neubiorev.2005.06.001

Campos, B., Shiota, M. N., Keltner, D., Gonzaga, G. C., \& Goetz, J. L. (2013). What is shared, what is different? Core relational themes and expressive displays of eight positive emotions. Cognition and Emotion, 27(1), 37-52. https://doi.org/10.1080/02699931.2012.683852

Cantor, N., \& Sanderson, C. A. (1999). Life task participation and well-being: The importance of taking part in daily life. In D. Kahneman, E. Diener, \& B. Schwartz (Eds.), Well-being: Foundations of hedonic psychology (pp. 230-243). New York, NY: Russell Sage.

Carver, C. S. (2003). Pleasure as a sign you can attend to something else: Placing positive feelings within a general model of affect. Cognition and Emotion, 17(2), 241-261. https://doi.org/10.1080/02699930302294

Carver, C. S., \& Scheier, M. F. (1990). Origins and functions of positive and negative affect: A controlprocess view. Psychological Review, 97(1), 19-35. https://doi.org/10.1037/0033-295X.97.1.19

Carver, C. S., \& Scheier, M. F. (2001). On the self-regulation of behavior. New York, NY: Cambridge University Press.

Costa, P. T., Jr., McCrae, R. R., \& Zonderman, A. B. (1987). Environmental and dispositional influences on well-being: Longitudinal follow-up of an American national sample. British Journal of Psychology, 78(3), 299-306. https://doi.org/10.1111/j.2044-8295.1987.tb02248.x 
Damasio, A. (2018). The strange order of things: Life, feeling, and the making of culture. [Kindle DX version] Retrieved from Amazon.com.

Diener, E. (1984). Subjective well-being. Psychological Bulletin, 95(3), 542-575. http://dx.doi.org/10.1037/0033-2909.95.3.542

Diener, E., \& Biswas-Diener, R. (2008). Happiness: Unlocking the mysteries of psychological wealth. Malden, MA: Blackwell.

Diener, E., Emmons, R. A., Larsen, R. J., \& Griffin, S. (1985). The Satisfaction With Life Scale. Journal of Personality Assessment, 49(1), 71-75. https://doi.org/10.1207/s15327752jpa4901 13

Diener, E., Oishi, S., \& Tay, L. (Eds.) (2018). Handbook of subjective well-being. Salt Lake City, UT: DEF. www.nobascholar.com

Diener, E., Suh, E. M., Lucas, R. E., \& Smith, H. L. (1999). Subjective well-being: Three decades of progress. Psychological Bulletin, 125(2), 276-302. https://doi.org/10.1037/0033-2909.125.2.276

Disabato, D. J., Goodman, F. R., Kashdan, T. B., Short, J. L., \& Jarden, A. (2016). Different types of wellbeing? A cross-cultural examination of hedonic and eudaimonic well-being. Psychological Assessment, 28(5), 471-482. https://doi.org/10.1037/pas0000209

Dreisbach, G., \& Goschke, T. (2004). How positive affect modulates cognitive control: Reduced perseveration at the cost of increased distractibility. Journal of Experimental Psychology: Learning, Memory, and Cognition, 30(2), 343-353. https://doi.org/10.1037/0278-7393.30.2.343

Emmons, R. A. (1986). Personal strivings: An approach to personality and subjective well-being. Journal of Personality and Social Psychology, 51(5), 1058-1068. https://doi.org/10.1037/0022-3514.51.5.1058

Fredrickson, B. L. (2001). The role of positive emotions in positive psychology: The broaden-and-build theory of positive emotions. American Psychologist, 56(3), 218-226. https://doi.org/10.1037/0003066X.56.3.218

Fredrickson, B. L. (2016). The eudaimonics of positive emotions. In J. Vittersø (Ed.), Handbook of eudaimonic well-being (pp. 183-190). Cham, Switzerland: Springer International. https://doi.org/10.1007/978-3-319-42445-3 12

Gable, P. A., \& Harmon-Jones, E. (2008). Approach-motivated positive affect reduces breadth of attention. Psychological Science, 19(5), 476-482. https://doi.org/10.1111/j.1467-9280.2008.02112.x

Gallagher, M. W., Lopez, S. J., \& Preacher, K. J. (2009). The hierarchical structure of well-being. Journal of Personality, 77(4), 1025-1050. https://doi.org/10.1111/j.1467-6494.2009.00573.x

Harmon-Jones, E., Gable, P. A., \& Price, T. F. (2013). Does negative affect always narrow and positive affect always broaden the mind? Considering the influence of motivational intensity on cognitive scope. Current Directions in Psychological Science, 22(4), 301-307. https://doi.org/10.1177/0963721413481353

Harmon-Jones, E., Price, T. F., Gable, P. A., \& Peterson, C. K. (2014). Approach motivation and its relationship to positive and negative emotions. In M. M. Tugade, M. N. Shiota, \& K. N. Kirby (Eds.), Handbook of positive emotions (pp. 103-118). New York, NY: Guilford.

Haybron, D. M. (2008). The pursuit of unhappiness: The elusive psychology of well-being. Oxford, UK: Oxford University Press.

Haybron, D. M. (2016). The philosophical basis of eudaimonic psychology. In J. Vittersø (Ed.), Handbook of eudaimonic well-being (pp. 27-53). Cham, Switzerland: Springer International. https://doi.org/10.1007/978-3-319-42445-3 2

Headey, B. (2008). Life goals matter to happiness: A revision of set-point theory. Social Indicators Research, 86(2), 213-231. https://doi.org/10.1007/s11205-007-9138-y

Hellevik, O. (2016). Extreme nonresponse and response bias. Quality \& Quantity, 50(5), 1969-1991. https://doi.org/10.1007/s11135-015-0246-5

Henderson, L. W., \& Knight, T. (2012). Integrating the hedonic and eudaimonic perspectives to more comprehensively understand wellbeing and pathways to wellbeing. International Journal of Wellbeing, 2(3), 196-221. https://doi.org/10.5502/ijw.v2i3.3

Hsee, C. K., \& Abelson, R. P. (1991). Velocity relation: Satisfaction as a function of the first derivative of outcome over time. Journal of Personality and Social Psychology, 60(3), 341-347.

http://psycnet.apa.org/doi/10.1037/0022-3514.60.3.341 
Huta, V., \& Waterman, A. S. (2014). Eudaimonia and its distinction from hedonia: Developing a classification and terminology for understanding conceptual and operational definitions. Journal of Happiness Studies, 15(6), 1425-1456. https://doi.org/10.1007/s10902-013-9485-0

IPIP. (2002). International Personality Item Pool: A scientific collaboratory for the development of advanced measures of personality and other individual differences. http://ipip.ori.org/

Jahoda, M. (1958). Current concepts of positive mental health. New York, NY: Basic Books.

Johannessen, K. B., Oettingen, G., \& Mayer, D. (2012). Mental contrasting of a dieting wish improves selfreported health behaviour. Psychology E Health, 27(Suppl. 2), 43-58. https://doi.org/10.1080/08870446.2011.626038

Kaftan, O. J., \& Freund, A. M. (2018). The way is the goal: The role of goal focus for successful goal pursuit and subjective well-being. In E. Diener, S. Oishi, \& L. Tay (Eds.), Handbook of well-being. Salt Lake City, UT: DEF. https://www.nobascholar.com/chapters/20/download.pdf

Kahneman, D. (1999). Objective happiness. In D. Kahneman, E. Diener, \& N. Schwarz (Eds.), Well-being: The foundations of hedonic psychology (pp. 3-25). New York, NY: Russell Sage.

Kappes, A., Singmann, H., \& Oettingen, G. (2012). Mental contrasting instigates goal pursuit by linking obstacles of reality with instrumental behavior. Journal of Experimental Social Psychology, 48(4), 811818. https://doi.org/10.1016/i.jesp.2012.02.002

Kashdan, T. B., Biswas-Diener, R., \& King, L. A. (2008). Reconsidering happiness: The costs of distinguishing between hedonics and eudaimonia. The Journal of Positive Psychology, 3(4), $219-233$. https://doi.org/10.1080/17439760802303044

Kashdan, T. B., Rose, P., \& Fincham, F. D. (2004). Curiosity and exploration: Facilitating positive subjective experiences and personal growth opportunities. Journal of Personality Assessment, 82(3), 291-305. https://doi.org/10.1207/s15327752jpa8203 05

Kashdan, T. B., \& Steger, M. F. (2007). Curiosity and pathways to well-being and meaning in life: Traits, states, and everyday behaviors. Motivation and Emotion, 31(3), 159-173. https://doi.org/10.1007/s11031$\underline{007-9068-7}$

Kasser, T., \& Ryan, R. M. (2001). Be careful what you wish for: Optimal functioning and the relative attainment of intrinsic and extrinsic goals. In P. Schmuck \& K. M. Sheldon (Eds.), Life goals and wellbeing: Towards a positive psychology of human striving. Ashland, $\mathrm{OH}$ : Hogrefe \& Huber.

Keyes, C. L., \& Annas, J. (2009). Feeling good and functioning well: Distinctive concepts in ancient philosophy and contemporary science. The Journal of Positive Psychology, 4(3), 197-201. https://doi.org/10.1080/17439760902844228

Kirby, L., Tugade, M., Morrow, J., Ahrens, A., \& Smith, C. (2014). Vive la difference: The differentiation of positive emotional experience and well-being. In M. M. Tugade, M. N. Shiota, \& K. N. Kirby (Eds.), Handbook of positive emotions. (pp. 241-255). New York, NY: Guilford.

Klug, H. J., \& Maier, G. W. (2015). Linking goal progress and subjective well-being: A meta-analysis. Journal of Happiness Studies, 16(1), 37-65. https://doi.org/10.1007/s10902-013-9493-0

Koestner, R., Lekes, N., Powers, T. A., \& Chicoine, E. (2002). Attaining personal goals: Self-concordance plus implementation intentions equals success. Journal of Personality and Social Psychology, 83(1), 231244. https://doi.org/10.1037/0022-3514.83.1.231

Kruglanski, A. W., Shah, J. Y., Fishbach, A., Friedman, R., Chun, W. Y., \& Sleeth-Keppler, D. (2002). A theory of goal systems. Advances in Experimental Social Psychology, 34, 331-378. https://doi.org/10.1016/S0065-2601(02)80008-9

Little, B. R. (1989). Personal projects analysis: Trivial pursuits, magnificent obsessions, and the search for coherence. In D. M. Buss \& N. Cantor (Eds.), Personality Psychology (pp. 15-31). New York, NY: Springer.

Luhmann, M., \& Hennecke, M. (2017). The motivational consequences of life satisfaction. Motivation Science, 3(1), 51-75. https://doi.org/10.1037/mot0000048

MacIntyre, A. (2007). After virtue (3rd ed.). [Kindle DX version] Retrieved from Amazon.com.

MacLeod, A. K., Coates, E., \& Hetherton, J. (2008). Increasing well-being through teaching goal-setting and planning skills: Results of a brief intervention. Journal of Happiness Studies, 9(2), 185-196. https://doi.org/10.1007/s10902-007-9057-2 
Masicampo, E., \& Baumeister, R. F. (2013). Conscious thought does not guide moment-to-moment actions -it serves social and cultural functions. Frontiers in Psychology, 4. https://doi.org/10.3389/fpsyg.2013.00478

McGregor, I., \& Little, B. R. (1998). Personal projects, happiness, and meaning: On doing well and being yourself. Journal of Personality and Social Psychology, 74(2), 494-512. https://doi.org/10.1037/0022$\underline{3514.74 .2 .494}$

Nussbaum, M. C. (2001). Upheavals of thought: The intelligence of emotions. New York, NY: Cambridge University Press. https://doi.org/10.1017/CBO9780511840715

Oettingen, G., Marquardt, M. K., \& Gollwitzer, P. M. (2012). Mental contrasting turns positive feedback on creative potential into successful performance. Journal of Experimental Social Psychology, 48(5), 990996. https://doi.org/10.1016/j.jesp.2012.03.008

Oettingen, G., Mayer, D., \& Portnow, S. (2016). Pleasure now, pain later: Positive fantasies about the future predict symptoms of depression. Psychological Science, 27(3), 345-353. https://doi.org/10.1177/0956797615620783

Oettingen, G., Mayer, D., \& Thorpe, J. (2010). Self-regulation of commitment to reduce cigarette consumption: Mental contrasting of future with reality. Psychology E Health, 25(8), 961-977. https://doi.org/10.1080/08870440903079448

Oettingen, G., Pak, H.-j., \& Schnetter, K. (2001). Self-regulation of goal-setting: Turning free fantasies about the future into binding goals. Journal of Personality and Social Psychology, 80(5), 736-753. https://doi.org/10.1037/0022-3514.80.5.736

Oettingen, G., \& Reininger, K. M. (2016). The power of prospection: Mental contrasting and behavior change. Social E Personality Psychology Compass, 10(11), 591-604. https://doi.org/10.1111/spc3.12271

Oettingen, G., Stephens, E. J., Mayer, D., \& Brinkmann, B. (2010). Mental contrasting and the selfregulation of helping relations. Social Cognition, 28(4), 490-508. https://doi.org/10.1521/soco.2010.28.4.490

Oishi, S., Diener, E., \& Lucas, R. E. (2007). The optimum level of well-being: Can people be too happy? Perspectives on Psychological Science, 2(4), 346-360. https://doi.org/10.1111/j.1745-6916.2007.00048.x

Palys, T. S., \& Little, B. R. (1983). Perceived life satisfaction and the organization of personal project systems. Journal of Personality and Social Psychology, 44(6), 1221-1230. https://doi.org/10.1037/0022$\underline{3514.44 .6 .1221}$

Pham, L. B., \& Taylor, S. E. (1999). From thought to action: Effects of process-versus outcome-based mental simulations on performance. Personality and Social Psychology Bulletin, 25(2), 250-260. https://doi.org/10.1177/0146167299025002010

Pross, A. (2016). What is Life? How chemistry becomes biology. Oxford, UK: Oxford University Press.

Reeve, J. (1989). The interest-enjoyment distinction in intrinsic motivation. Motivation and Emotion, 13(2), 83-103. https://doi.org/10.1007/BF00992956

Russell, D. C. (2013). Virtue ethics, happiness, and the good life. In D. C. Russell (Ed.), The Cambridge companion to virtue ethics (pp. 7-28). Cambridge, UK: Cambridge University Press. https://doi.org/10.1017/CCO9780511734786.002

Ryan, R. M., \& Deci, E. L. (2001). On happiness and human potentials: A review of research on hedonic and eudaimonic well-being. Annual Review of Psychology, 52(1), 141-166. https://doi.org/10.1146/annurev.psych.52.1.141

Ryan, R. M., \& Deci, E. L. (2017). Self-determination theory: Basic psychological needs in motivation, development, and wellness. [Kindle DX version] Retrieved from Amazon.com.

Ryan, R. M., \& Martela, F. (2016). Eudaimonia as a way of living: Connecting Aristotle with selfdetermination theory. In J. Vittersø (Ed.), Handbook of eudaimonic well-being (pp. 109-122). Cham, Switzerland: Springer International. https://doi.org/10.1007/978-3-319-42445-3 7

Ryff, C. D. (1989). Happiness is everything, or is it? Explorations on the meaning of psychological wellbeing. Journal of Personality and Social Psychology, 57(6), 1069-1091. https://doi.org/10.1037/0022$\underline{3514.57 .6 .1069}$

Ryff, C. D. (2014). Psychological well-being revisited: Advances in the science and practice of eudaimonia. Psychotherapy and Psychosomatics, 83(1), 10-28. https://doi.org/10.1159/000353263 
Ryff, C. D. (2016). Beautiful ideas and the scientific enterprise: Sources of intellectual vitality in research on eudaimonic well-being. In J. Vittersø (Ed.), Handbook of eudaimonic well-being (pp. 95-107). Cham, Switzerland: Springer International. https://doi.org/10.1007/978-3-319-42445-3 6

Ryff, C. D., \& Singer, B. (1998). The contours of positive human health. Psychological Inquiry, 9(1), 1-28. https://doi.org/10.1207/s15327965pli0901 1

Ryff, C. D., \& Singer, B. H. (2008). Know thyself and become what you are: A eudaimonic approach to psychological well-being. Journal of Happiness Studies, 9(1), 13-39. https://doi.org/10.1007/s10902-0069019-0

Schimmack, U., Schupp, J., \& Wagner, G. G. (2008). The influence of environment and personality on the affective and cognitive component of subjective well-being. Social Indicators Research, 89(1), 41-60. https://doi.org/10.1007/s11205-007-9230-3

Schwartz, B., \& Wrzesniewski, A. (2016). Internal motivation, instrumental motivation, and eudaimonia. In J. Vittersø (Ed.), Handbook of eudaimonic well-being (pp. 123-134). Cham, Switzerland: Springer International. https://doi.org/10.1007/978-3-319-42445-3 8

Sheeran, P., Harris, P., Vaughan, J., Oettingen, G., \& Gollwitzer, P. M. (2013). Gone exercising: Mental contrasting promotes physical activity among overweight, middle-aged, low-SES fishermen. Health Psychology, 32(7), 802-809. https://doi.org/10.1037/a0029293

Sheldon, K. M. (2018). Understanding the good life: Eudaimonic living involves well-doing, not wellbeing. In J. Forgas \& R. Baumeister (Eds.), The social psychology of living well (pp. 116-136). New York, NY: Routledge.

Sheldon, K. M., \& Houser-Marko, L. (2001). Self-concordance, goal attainment, and the pursuit of happiness: Can there be an upward spiral? Journal of Personality and Social Psychology, 80(1), 152-165. https://doi.org/10.1037/0022-3514.80.1.152

Sheldon, K. M., \& Lyubomirsky, S. (2006). Achieving sustainable gains in happiness: Change your actions, not your circumstances. Journal of Happiness Studies, 7(1), 55-86. https://doi.org/10.1007/s10902-005-0868-8

Shiota, M. N., Thrash, T. M., Danvers, A. F., \& Dombrowski, J. T. (2014). Transcending the self: Awe, elevation, and inspiration. In M. M. Tugade, M. N. Shiota, \& K. N. Kirby (Eds.), Handbook of positive emotions (pp. 362-395). New York, NY: Guilford.

Silvia, P. J., McCord, D. M., \& Gendolla, G. H. (2010). Self-focused attention, performance expectancies, and the intensity of effort: Do people try harder for harder goals? Motivation and Emotion, 34(4), 363370. https://doi.org/10.1007/s11031-010-9192-7

Smith, C. A., Tong, E. M. W., \& Ellsworth, P. C. (2014). The differentiation of positive emotional experience as viewed through the lens of appraisal theory. In M. M. Tugade, M. N. Shiota, \& K. N. Kirby (Eds.), Handbook of positive emotions (pp. 11-27). New York, NY: Guilford.

Steca, P., Monzani, D., Greco, A., D' Addario, M., Cappelletti, E., \& Pancani, L. (2016). The effects of shortterm personal goals on subjective well-being. Journal of Happiness Studies, 17(4), 1435-1450. https://doi.org/10.1007/s10902-015-9651-7

Straume, L. V., \& Vittersø, J. (2012). Happiness, inspiration, and the fully functioning person: Separating hedonic and eudaimonic well-being in the workplace. The Journal of Positive Psychology, 7(5), 387-398. https://doi.org/10.1080/17439760.2012.711348

Taylor, S. E., Pham, L. B., Rivkin, I. D., \& Armor, D. A. (1998). Harnessing the imagination: Mental simulation, self-regulation, and coping. American Psychologist, 53(4), 429-439. https://doi.org/10.1037/0003-066X.53.4.429

Tov, W. (2018). Well-being concepts and components. In E. Diener, S. Oishi, \& L. Tay (Eds.), Handbook of well-being. Salt Lake City, UT: DEF. https://www.nobascholar.com/chapters/12/download.pdf

Turner, S. A., Jr., \& Silvia, P. J. (2006). Must interesting things be pleasant? A test of competing appraisal structures. Emotion, 6(4), 670-674. https://doi.org/10.1037/1528-3542.6.4.670

Vittersø, J. (2013). Functional well-being: Happiness as feelings, evaluations, and functioning. In I. Boniwell, S. A. David, \& A. C. Ayers (Eds.), The Oxford handbook of happiness (pp. 227-244). Oxford, UK: Oxford University Press. https://doi.org/10.1093/oxfordhb/9780199557257.013.0017 
Vittersø, J. (2016). The feeling of excellent functioning: Hedonic and eudaimonic emotions. In J. Vittersø (Ed.), Handbook of eudaimonic well-being (pp. 253-276). Cham, Switzerland: Springer International. https://doi.org/10.1007/978-3-319-42445-3 17

Vittersø, J. (2018). Do it! Activity theories and the good life. In E. Diener, S. Oishi, \& L. Tay (Eds.), Handbook of well-being. Salt Lake City, UT: DEF. https://www.nobascholar.com/chapters/19

Vittersø, J., Oelmann, H. I., \& Wang, A. L. (2009). Life satisfaction is not a balanced estimator of the good life: Evidence from reaction time measures and self-reported emotions. Journal of Happiness Studies, 10(1), 1-17. https://doi.org/10.1007/s10902-007-9058-1

Vittersø, J., \& Søholt, Y. (2011). Life satisfaction goes with pleasure and personal growth goes with interest: Further arguments for separating hedonic and eudaimonic well-being. The Journal of Positive Psychology, 6(4), 326-335. https://doi.org/10.1080/17439760.2011.584548

Vittersø, J., Søholt, Y., Hetland, A., Thoresen, I. A., \& Røysamb, E. (2010). Was Hercules happy? Some answers from a functional model of human well-being. Social Indicators Research, 95(1), 1-18. https://doi.org/10.1007/s11205-009-9447-4

Waterman, A. S. (1993). Two conceptions of happiness: Contrasts of personal expressiveness (eudaimonia) and hedonic enjoyment. Journal of Personality and Social Psychology, 64(4), 678-691. https://doi.org/10.1037/0022-3514.64.4.678

Waterman, A. S., \& Schwartz, S. J. (2013). Eudaimonic identity theory. In A. S. Waterman (Ed.), The best within us: Positive psychology perspectives on eudaimonia (pp. 99-118). Washington, DC: American Psychological Association. https://doi.org/10.1037/14092-006

WHO Regional Office for Europe. (2012). Measurement of and target-setting for well-being. Second meeting of the expert group, Paris, 25-26 June 2012. Copenhagen: WHO Regional Office for Europe.

Wiese, B. S., \& Freund, A. M. (2005). Goal progress makes one happy, or does it? Longitudinal findings from the work domain. Journal of Occupational and Organizational Psychology, 78(2), 287-304.

https://doi.org/10.1348/096317905X26714 